$\left(\begin{array}{llll}\text { Jpn. } & J_{\text {. }} & \text { Hosp. } & \text { Pharm. } \\ \hline \text { 22(1) } & 60-71 & \begin{array}{c}\text { 論 } \\ \text { (1996) }\end{array}\end{array}\right)$

\title{
Time-Series Study of the Collection and Utilization of Drug Information $\dagger^{1}$
}

\author{
KEIKO BUTATSU* $\dagger^{2}$, NORIKO OHHARA $\dagger^{2}$, \\ MASAYASU SUGIHARA $\dagger^{2}$, and KENJI FUKUMURO $\dagger^{3}$ \\ Department of Pharmacy, Tokyo Women's Medical College $\dagger^{2}$ \\ Faculty of Pharmaceutical Science, Science University of Tokyo ${ }^{3}$ \\ Received June 2, 1995 \\ (Accepted December 10, 1995 )
}

The collection of drug information is indispensable for the efficient supply of information, which is the final goal of Drug Information(DI) activities, but the collected information has no significance if it can not be utilized. Therefore, in order to study a time-series survey on how information collected in the DI Room can be utilized and establish a rational information collection and utilization system, we conducted a pilot study on interferon (IFN) preparations, which have been the subject of many questions to the DI Room in recent years.

The study period covered about 16 years from the time when the DI Room was established and collection of information started in 1978 until 1994. The utilization of information was considered to occur when surveys were performed and replies were given to questions on IFN directed to the DI Room during this period. The number of time-series utilizations of collected information and the hit rates, as well as the period from collection until utilization of the information, were calculated.

In the time-series study, differences in the utilization conditions were found depending on the contents of the information. Because new adverse drug reactions suddenly appeared with the increased dose associated with the addition of hepatitis $\mathrm{C}$ as an indication of IFN, the number of cases of collection and utilization of information on adverse drug reactions also increased after addition of the indication, and the hit rates for the collected information were quite good. The appearance of new information resulted in a time-series related reduction in the utilization of old information and shortened the time from collection until utilization. Definite information on stability after dissolving of the preparation, the prick test, etc. was utilized no matter what the time of collection.

Because various factors affect the collection and utilization of information, including differences due to the properties of the preparation and the contents of the information, the DI member must bear these factors in mind and endeavor to collect information aimed at the reliable supply of information.

Key words - collected information, utilized information; time-series change

$\dagger^{1}$ Presented at the 115th General Meeting of the Japan Pharmaceutical Association (Sendai, 1995)

$\dagger^{2}$ 東京都新宿区河田町 8-1；8-1, Kawada-cho, Shinjuku-ku, Tokyo, 162 Japan

$\dagger^{3}$ 東京都新宿区市谷船河原町 $12 ； 12$, Ichigayafunakawara-cho, Shinjuku-ku, Tokyo, 162 Japan 


\section{Introduction}

Collection of the latest drug information is indispensable for the rapid and reliable supply of information, which is the main objective of Drug Information (DI) activities, but the collected and accumulated information has no significance unless it is utilized effectively.

The amount of information concerning a certain preparation increases with time from development until postmarketing, but the time-series changes in the generation and utilization of information depend on various factors, including the inherent properties of individual drugs or preparations, the symptoms and numbers of patients concerned, and the frequency of prescribing the drug. The scale of the time-series changes appears to differ in accordance with the type of the information. Therefore, a pilot study was performed on interferon(IFN) preparations, which have been the subject of many questions to the DI Room in recent years, with the objective of providing a rational information collection and utilization system and contributing to the proper use of drugs by means of a time-series survey on how various types of information collected in the past in the DI Room, Department of Pharmacy, Tokyo Women's Medical College are utilized.

\section{Methods}

\section{Survey period and method}

The survey period was about 16 years from the time when the DI Department was established and collection of information started in October 1978 until December 1994. The utilization of information was considered to occur when surveys were conducted and replies were made to questions on IFN directed to the DI Room during the survey period. In this study, utilization of information refers to selection of the information concerned from the information collected and includes cases when replies were given on the basis of the contents of the information and also when the contents of the information were inadequate but the information was used as reference when the reply was made.

\section{Range of collected information}

The collected information to be utilized included packagte inserts, drug interview forms, the sources, publications of the Ministry of Health and Welfare, and papers evaluated and collected on the basis of literature monitoring by the DI Room. Publications such as drug directories were excluded from the collected information in the present study.

\section{Study of time-series changes in the numbers of surveys by survey items in response to questions and} factors influencing them

The surveys in response to questions on IFN were classified by item, and the profiles of time-series changes in the number of surveys for each item were studied. The influencing factors which formed the background for the survey items with a large scale of time-series changes were analyzed.

\section{Study of time-series changes in the number of utilizations and hit rates of collected information and} factors influencing them

In the case of survey items for which there were many questions, the number of collected information utilized at the time of the surveys and replies was taken as the number of utilizations, and the hit rate was the percentage of the number of utilizations among the cumulative number of information collected at the time. The profiles of 
time-series changes in each case were studied together with the factors affecting the time-series changes.

\section{Study on time-series changes in the period from collection until utilization of the information}

The number of years from collection until utilization of the information in the DI Room was calculated for each survey item, and the profiles of time-series changes were studied. Information not utilized, in spite of applicable content, was surveyed and the utilization conditions were studied.

\section{Results and Discussion}

\section{Study of time-series changes in the number of surveys by survey item and the factors influencing them}

(1) Classification of the contents of surveys in response to questions

The contents of surveys in response to questions on IFN were classified by item and the number of surveys in each case are shown in Table 1. Questions on IFN were directed to the DI Room from 1985 when Japan's first IFN preparation Feron went on the market and in the 10 years until December 1994, a total of 126 surveys had been performed. Among these surveys, 51 or $40.5 \%$ of the total concerned adverse drug reactions, 23 or 18.3 $\%$ concerned indications or directions and dosage, 11 were requests for package inserts, 10 concerned the stability of the preparation after dissolution, six concerned the prick test method and four the health insurance reimbursement price of the drug.

(2) Study of time-series changes in the number of surveys by survey item

Fig. 1 shows profiles of time-series changes in the number of surveys by survey item. The survey items with a large scale change were related to adverse drug reactions and indications, directions and dosage. The number of surveys on adverse drug reactions shown by open circles $(O)$ were few until 1990 but then gradually increased with a peak of 16 in 1993, fell to eight in 1994. There were nine surveys concerning indications, directions and dosages shown by open squares $(\square)$ in 1992 and less than three in other years.

(3) Study of the numbers of adverse drug reaction surveys by symptom and time-series changes

Table 2 shows the 51 surveys on adverse drug reactions by symptom. There were four cases each of central nervous system disorders such as convulsion and encephalopathy, fever and skin disorders such as skin eruption and alopecia ; three cases each of renal failure, myelosuppression including leukopenia and thrombopenia ; and two each of pancreatitis including hyperamylasemia and ECG abnormalities. One case each of hyperthyroidism,

Table 1. Classification of Contents of Surveys in Response to Questions on IFN (1985 1994)

\begin{tabular}{lc}
\hline \multicolumn{1}{c}{ Content of Survey } & Na $(\%)$ \\
\hline Adverse drug reactions & $51(40.5)$ \\
Indication, directions and dosage & $23(18.3)$ \\
Requests for package inserts & $11(8.7)$ \\
Stability of the preparation after dissolution & $10(7.9)$ \\
Prick test method & $6(4.8)$ \\
Price of the drug & $4(3.2)$ \\
Others & $21(16.6)$ \\
\hline Total & $126(100)$ \\
\hline
\end{tabular}




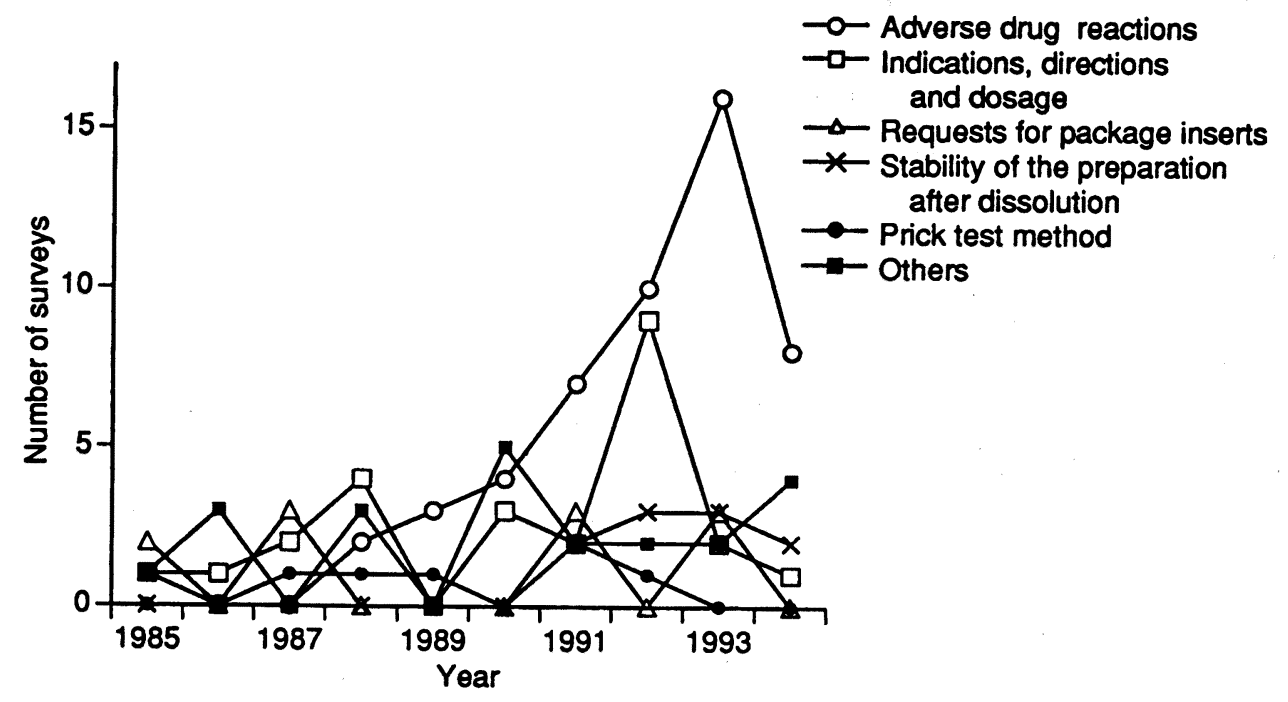

Fig. 1. Time-Series Changes in Number of Surveys by Survey ltem

Table 2. Contents of Surveys on Adverse Drug Reactions by Symptom

\begin{tabular}{lc|lc}
\hline Symptom & No & Symptom & No \\
\hline Central nervous system disorder & 4 & Liver disorder & 1 \\
Fever & 4 & Hyperglycemia & 1 \\
Skin disorder & 4 & Myalgia & 1 \\
Renal failure & 3 & Tinnitus & 1 \\
Myelosupression & 3 & Ocular hyperemia & 1 \\
Pancreatitis, Hyperamylasemia & 2 & Cough & 1 \\
ECG abnomality & 2 & Adverse drug reactions in general & 8 \\
Hyperthyroidism & 1 & Others & 13 \\
Peripheral neuropathy & 1 & Total & 51 \\
\hline
\end{tabular}

peripheral neuropathy, liver disorder, hyperglycemia, myalgia, tinnitus and ocular hyperemia were also found. There were eight surveys on adverse drug reactions in general, and four on interactions, including those on interstitial pneumonia due to concomitant use with the Chinese herbal preparation Shousaiko-to.

In contrast to the wide diversity of the adverse drug reactions, there were not many adverse drug reaction symptoms and in the time-series study, there was no concentration of a specific adverse drug reaction at a certain time. For example , the survey times for central nervous system disorders were diverse : February 1988, July 1989, May 1992 and May 1994. It was evident that a succession of different adverse drug reactions came out one after another.

When the department identified to be asking the questions and the contents of the surveys of adverse drug reactions were examined, most of the questions were from departments concerned with the indications of IFN, including 10 from the department of hematology (myelosuppression, renal failure, peripheral neuropathy, 
pancreatitis, ECG abnormalities, interactions, etc.), followed by the department of gastroentrology with five (pancreatitis, hyperthyroidism, interactions, etc.) endocrinology with two (liver disorder and alopecia) and one each from nephrology (myalgia) and dermatology (skin rash). The other questions came from departments where patients had been examined because of side effects and consisted of two each from neurology (encephalopathy, dizziness), respiratory medicine (pneumonia from concomitant administration of Shousaiko -to, etc.), diabetes center (hyperglycemia, etc.) and otolarynology (tinnitus, etc.), and one each from cardiology (ECG abnormalities), ophthalmology (ocular hyperemia) and a request for examination from another hospital (alopecia).

(4) Study of factors affecting time-series changes

Fig. 2 shows the profiles of time-series changes in the numbers of papers on adverse drug reactions of IFN collected and evaluated through literature monitoring undertaken by the DI Room since around 1980, the number of papers on adverse drug reactions of IFN retrieved from MEDLINE and JMEDICINE, and the total sales of four IFN products (Feron, Sumiferon, Canferon and Intron A) which are indicated for chronic active heptitits $\mathbf{C}$ (hepatitis $\mathrm{C}$ ) used to analyze the factors which cause time-series changes in the number of surveys on adverse drug reactions.

The numbers of MEDLINE retrievals shown by open circles $(O)$ increased almost linearly from around 1980 , but the number of retrievals from JMEDICIN, which includes the main medical journals containing papers published in Japan shown by open squares $(\square)$, the number of papers collected in the DI Room shown by open triangles $(\Delta)$ and the total sales of the four IFN products shown by an "X" mark all revealed sharp increases since 1992 when hepatitis $\mathrm{C}$ was added as an indication for the four IFN products. The number of papers in 1993 had increased to about 5-fold that in 1991, and the total sales (based on the reimbursement

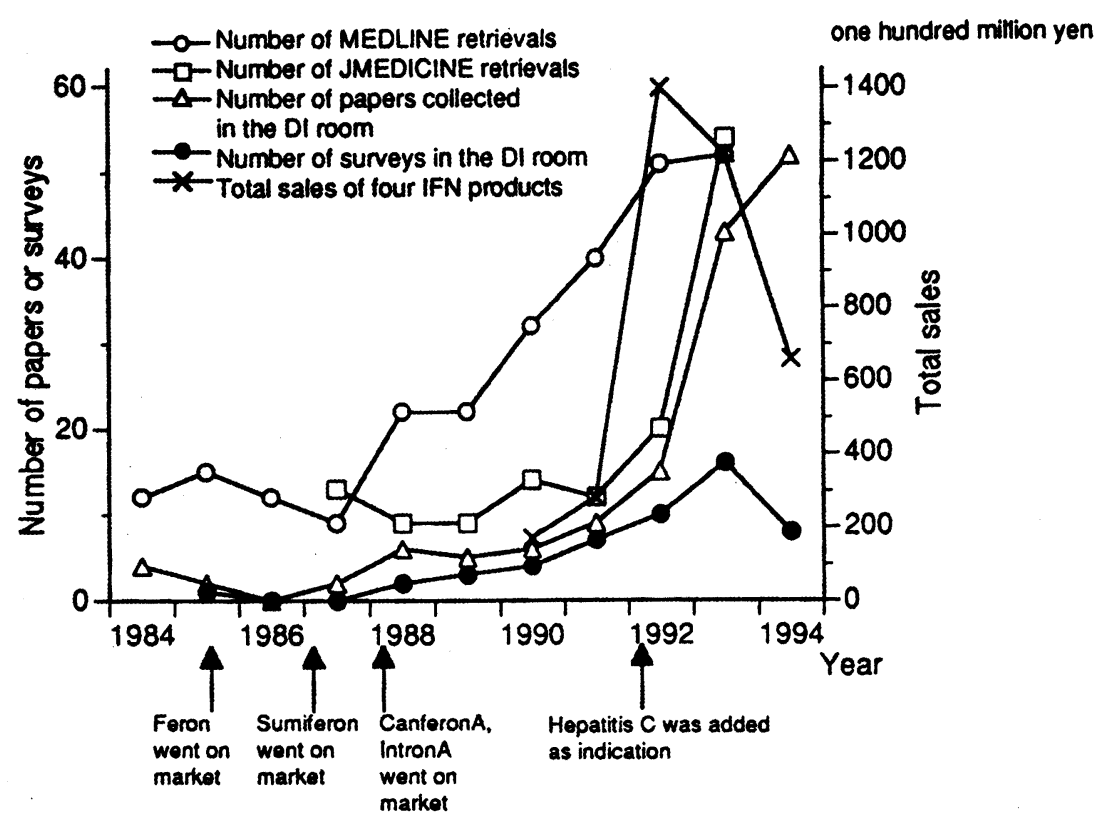

Fig. 2. Time-Series Changes in Number of Papers on IFN Adverse Drug Reactions and Total Sales of Four IFN Products 
price) in 1992 were about 5 -fold those in 1991.

Therefore, since increases in the number of patients taking IFN preparations have resulted in sharp increase in the doses and frequency of use of IFN and revealed diverse adverse drug reactions of IFN itself, this led to time-series changes in the number of adverse drug reaction surveys in the DI Room. The decrease in the sales of IFN preparations since 1993 appears to be due to such factors as a reduction in the frequency of use associated with the decrease in the number of patients taking IFN, and the lower reimbursement prices. The number of surveys on IFN in the DI Room started to drop in 1994 and , in addition to the reduced frequency of use of IFN, one reason for this is assumed to be that information on the adverse drug reactions of IFN, including that from the DI Room, is well known in the hopsital since safety information, especially that on adverse drug reactions, is processed just after collection and evaluation in the DI room and reported repeatedly in the monthly DI journal in the hospital. Therefore, the active information service such as DI journal in hospital is considered to be more important in DI activities in future.

The time-series changes in the number of surveys on indications, directions and dosage also appear to be affected by the added indication in the same way as in the case of adverse drug reactions.

\section{Study of time-series changes in the numbers of utilizations and hit rates of collected information and} factors affecting them

(1) Study on adverse drug reaction information

Fig. 3 shows the time-series changes in the degree of utilization of information collected in the DI Room in response to questions on adverse drug reactions which most frequently lead to surveys.

The collected information subject to utilization since 1982 totalled 191 items, including five items on Ministry of Health and Welfare publication, Information on Adverse Reactions to Drugs, 34 items on package inserts and 152 on papers collected by literature monitoring in the DI Room. Concerning time-series changes in

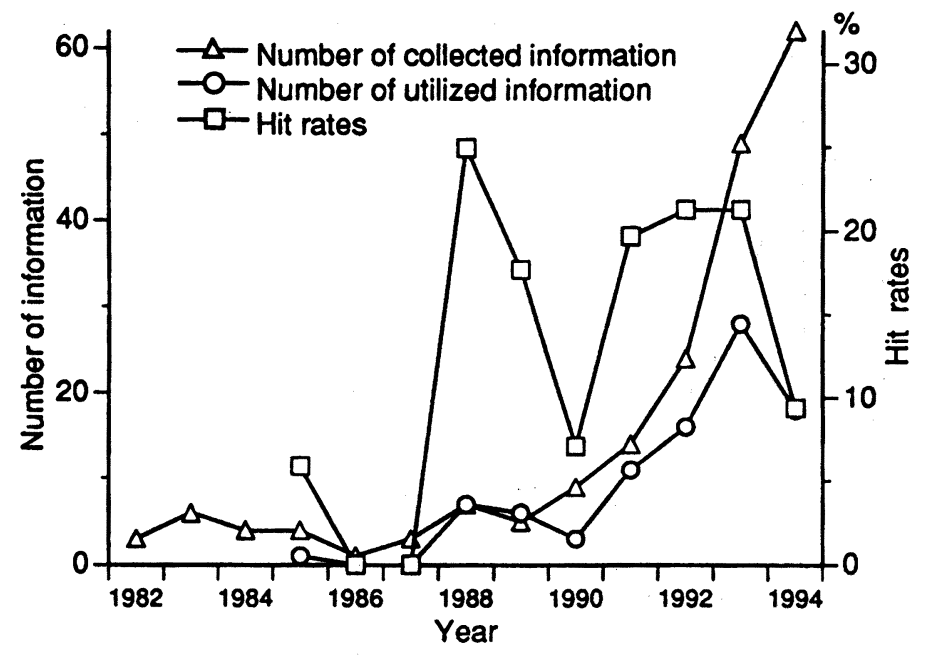

Fig. 3. Time-Series Changes in Number of Utilizations and Hit Rates of Collected Adverse Drug Reaction Information 
the number of information collected at the time shown by open triangles $(\Delta)$, the number collected annually up to 1990 were less than 10 but from 1991, there was a sharp increase to 62 in 1994 . Profiles of the time-series changes are shown by open circles $(O)$ for the number of utilizations of information and by open squares ( $\square$ ) for the hit rates.

The number of utilizations and the hit rates both showed peaks at two sites in 1988 and 1993 . The number of utilizations in 1988 was seven and the increase was small, but the marketing of gene recombinant IFN preparations such as Canferon and Intron $A$ appeared to be a factor. The cumulative number of collected information at that time was 28 , and the hit rate became $25.0 \%$. The number of utilizations in 1993 rose to 28 , but because of the large amount of adverse drug reaction information generated associated with the addition of hepatitis $\mathrm{C}$ as an indication, the cumulative number of information collected was high at 127 at that time, and the hit rate was only $21.3 \%$, lower than that in 1988 . Therefore, it is evident that about one fourth $(1 / 4)$ of the collected information was utilized in the years with high hit rates. The total number of utilizations was 91 and the total utilization rate was 91 out of 191 of $47.1 \%$, which was rather high.

(2) Study on information concerning indications, directions and doses

The information collected for utilization with respect to confirmation of indications, directions and dosage, which accounted for the most surveys following adverse drug reactions, and requests for package inserts, included 34 package inserts for the previously mentioned four products. Fig. 4 shows the time-series changes in the number of utilizations of these package inserts and the hit rates in these surveys. The profiles of the number of utilizations are shown by the open circles $(O)$ and the hit rates by the open squares $(\square)$

Two peaks were seen in 1987 and 1992 . The increase in the number of utilizations in 1987 mainly consisted of requests to obtain package insets. The factors involved were considered to be the addition of hepatitis $B$ as an indication of Feron and the fact that Sumiferon had just been marketed. There were five utilizations and only

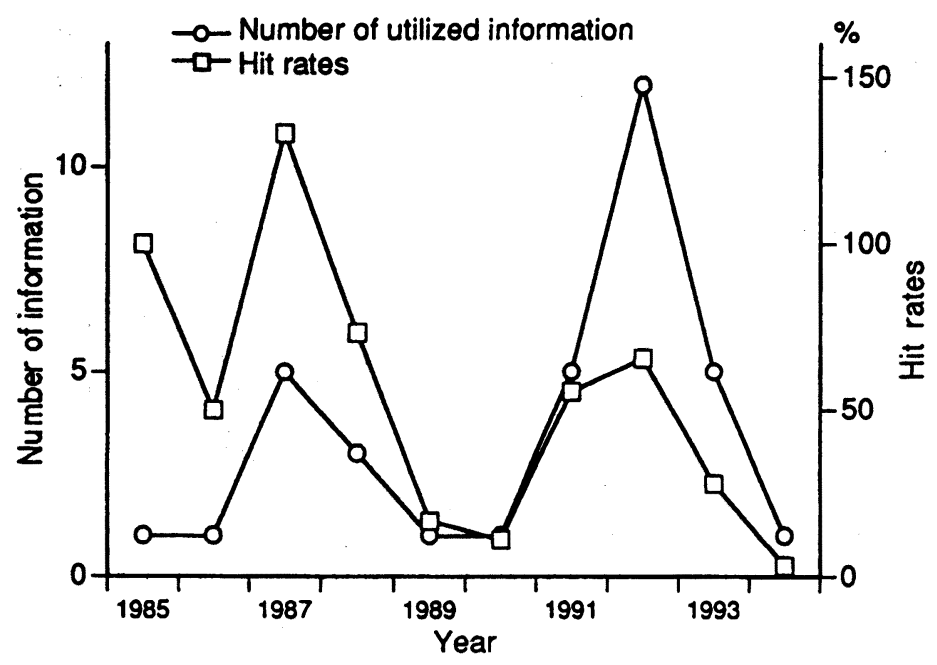

Fig. 4. Time-Series Changes in Number of Utilizations and Hit Rates of Collected Package Inserts on Indications, Directions and Dosage 
three items of information collected at that time but since one package insert was utilized several times, the hit rates exceeded $100 \%(133.3 \%)$. The increase in the number of utilizations in 1992 when hepatitis $\mathrm{C}$ was added as an indication for all four products was mainly related to confirming the indication. The number of utilizations was high at 11 . The hit rate at the time also showed a high value of $65.5 \%$. It is clear that about two thirds $(2 / 3)$ of the information collected was utilized.

\section{3 . Time-series study of the period from collection until utilization of information}

Fig. 5 shows the time lag, i. e., the number of years from collection until utilization for a total of 90 papers on adverse drug reactions collected and utilized in surveys. Within one year after collection, 48 of the 90 papers or $53.5 \%$ of the total were utilized ; the figure increased to $72.2 \%$ within 2 years and $83.3 \%$ within 4 years. The frequency of utilization of relatively old papers from after 5 years was low.

Fig. 6 gives actual examples of the time relation between information collection and utilization. The left side shows the time of collection of the papers on adverse drug reactions and the right side the time of surveys in response to questions. The solid lines connecting the two sides show papers utilized at the time of the surveys and the broken lines lines show papers which were not utilized in spite of applicable information. The longer the line, the longer the number of years until utilization. For example, in response to questions on renal failure in March 1985 and February 1988, papers ${ }^{1-5)}$ collected in March 1984 and June 1985 were utilized, but those were not still being utilized for a survey in October 1992. In response to a question on thyroid disorders in December 1994, Ministry of Health and Welfare Information on Adverse Reactions to Drugs No. 115 in July 1992 and papers ${ }^{6-12)}$ collected in October 1991 and from 1992 were used, but those in July 1985 and August 1989 were not used. In response to a question on central nervous system disorders, papers ${ }^{13-19)}$ utilized on epilepsy in February 1988 and on encephalopathy in May 1992 were completely different, and since many new papers on central nervous system disorders have been collected thereafter, the possibility of utilization of old papers in

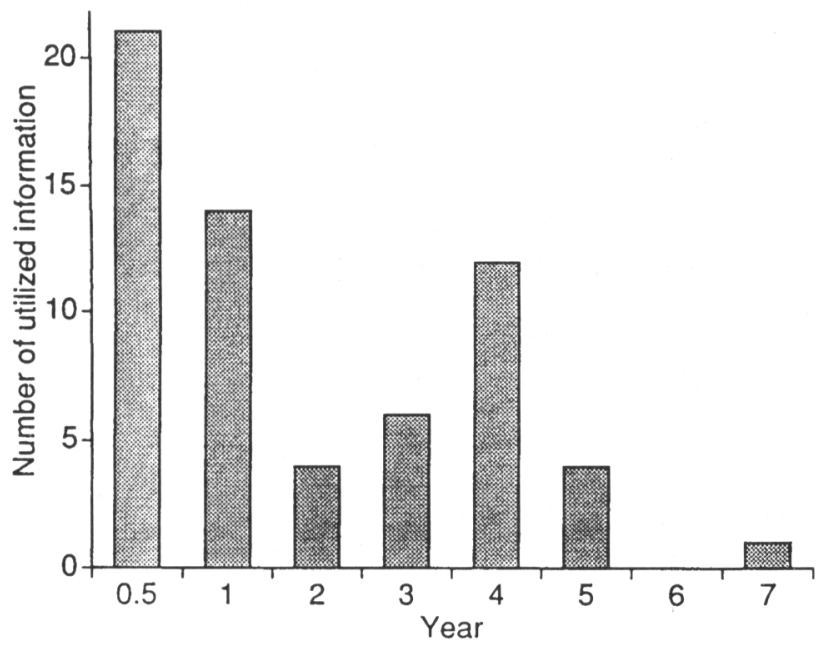

Fig. 5. Time Lag from Collection until Utilization of Papers on Adverse Drug Reactions 


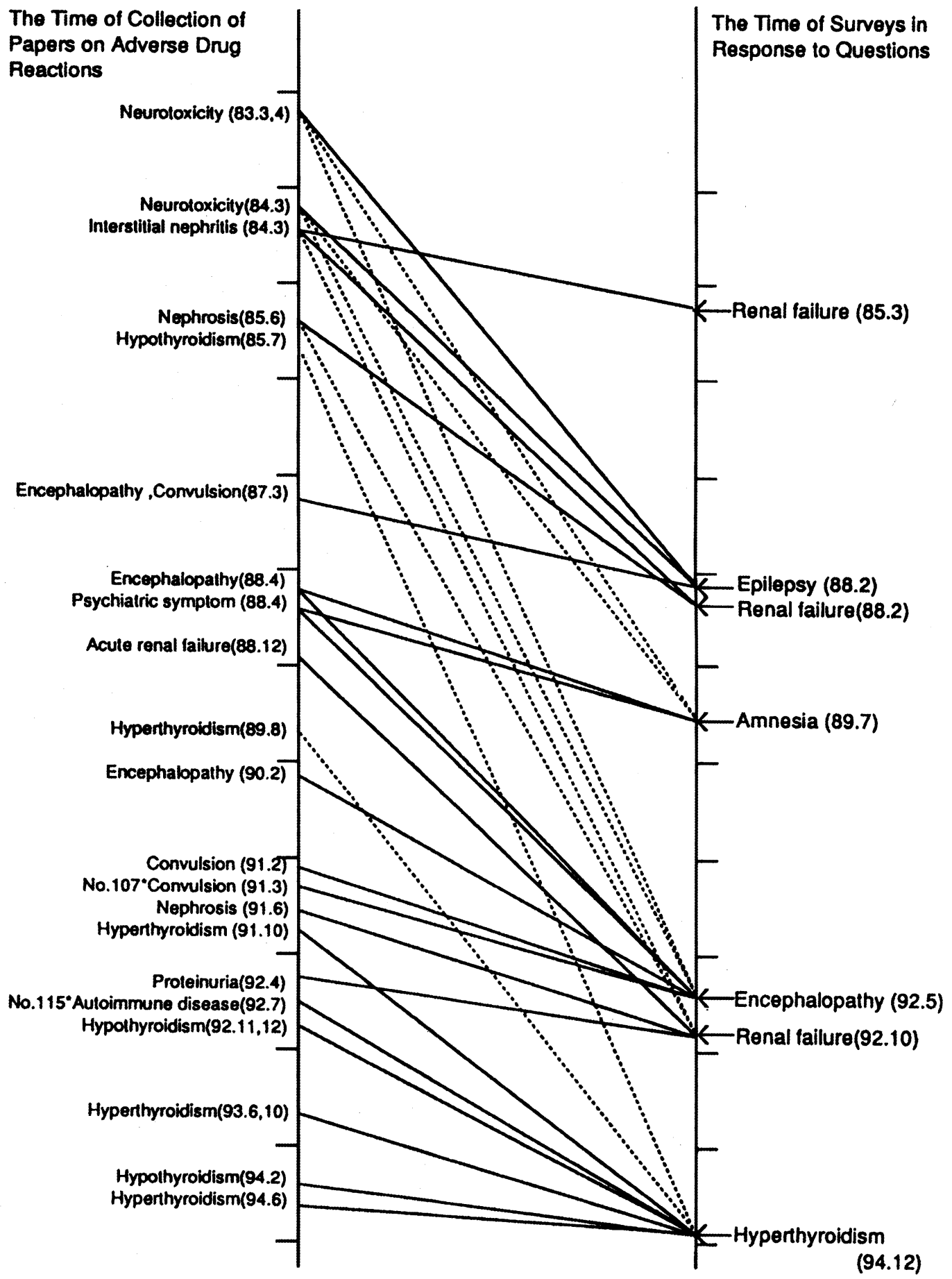

Information of Adverse Reactions to Drugs published by Ministry of Health and Weliare

Fig. 6. Time Relation between Collection and Utilization of Papers on Adverse Drug Reactions 
future is low.

The reason for this is that new papers appear on the basis of old papers and include old information, and new papers are given priority when information is evaluated. Since a large amount of information has appeared over a short period of time on the adverse drug reactions of IFN, the subject of the present study, this phenomenon appears to be especially marked for these drugs. Therefore, in future, it will be necessary to investigate methods of managing old papers with a reduced frequency of utilization.

Fig. 7 shows plots of the time lag from collection to utilization of package inserts on indications, directions

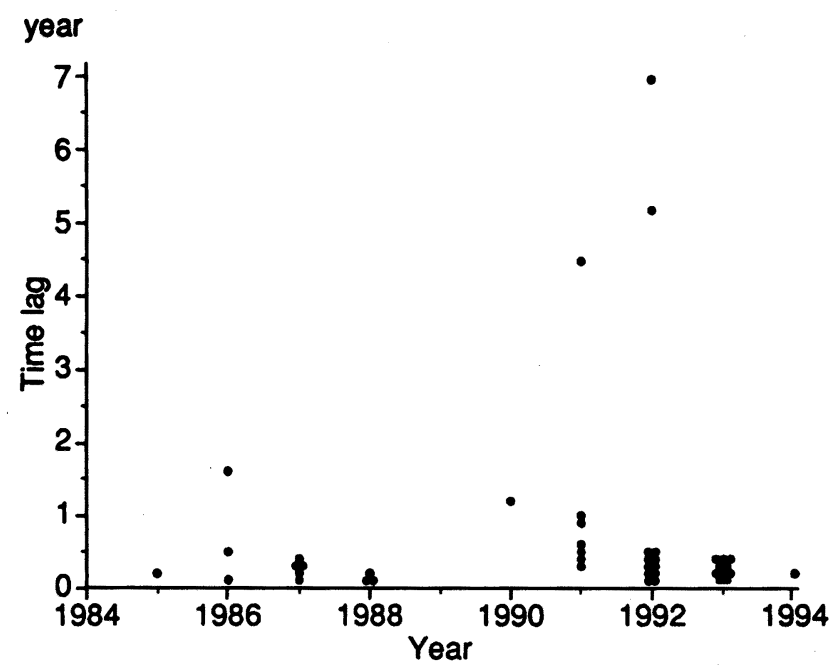

Fig. 7. Time-Series Changes in Time Lag from Collection until Utilization of Package Inserts on Indications, Directions and Doses

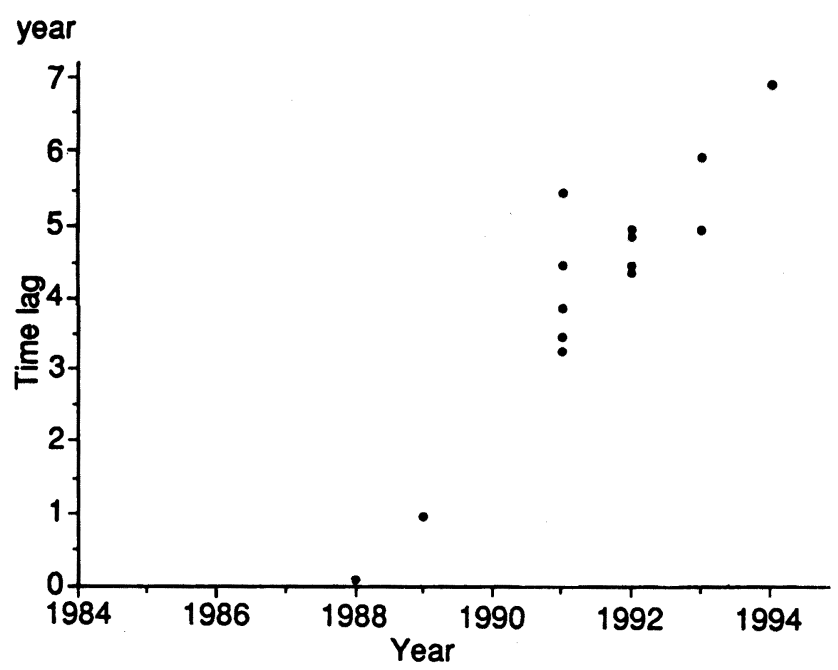

Fig. 8. Time-Series Changes in Time Lag from Collection until Utilization of Information on Prick Test Method, etc. 
and doses for each case. Most of the package inserts were utilized within one year after collection and the phenomenon of giving priority to the utilization of the most recent information was confirmed, but it is essential to preserve old package inserts because they are legal documents and surveys can be performed by going back to the revised contents and revision times using the old package inserts.

In contrast, Fig. 8 shows the plots of the time lag from collection to utilization of related information collected from interview forms or during interviews for surveys on stability of the preparation after dissolution or the prick test method, as well as the profile of time-series changes. A definite correlation between the timesseries of the numbers of survey years and the time lag from information collection to utilization was found, and since this is definite information which can be utilized anytime once it is collected, the importance of collection of information at the time of marketing was again confirmed.

\section{Conclusion}

The following points were suggested from the pilot study on IFN preparations with striong pharmacological action.

1) There are various factors which influence time-series changes in the number of collections and utilizations of information, including inherent characteristics of the preparation itself such as the appearance of adverse drug reactions, and increases in the numbers of patients and the frequency of use which are typical for added indications.

2 ) It is indispensable to establish an information collection system as part of the DI activities since the collected information was quite effectively utilized.

3 ) The time from collection until utilization of information differed depending on the contents of the information. Concerning adverse drug reactions, the appearance of new information reduced the utilization of old information, and the time from collection to utilization was shortened. Therefore, the necessity of collecting the latest information and studying ways to periodically sort through and dispose of old information with a reduced frequency of use was suggested. However, since definite information on the physical properties, etc. of the preparation can be utilized anytime once it is collected, the importance of collection of information at the time of marketing was reconfirmed.

Since there are various factors which affect the collection and utilization of drug information, DI members must bear these factors in mind and endeavor to collect information aimed at reliable supply of information, including the active information service such as DI journal in hospital and hospital formulary.

\section{References}

1) S. D. Averbuch, H. A. Austin III, S. A. Sherwin, T. Antonovych, P. A. Bunn, Jr. and D. L. Longo, N. Engl. J. Med., 310, 32-35 (1984).

2 ) P. Selby, J. Kohn, J. Raymond, I. Judson and T. M. Wain, Br. Med. J., 290, 1180 (1985).

3 ) B. H. Ault, F. B. Stapleton, L. Gaber, A. Martin, S. Roy III and S. B. Murphy, N. Engl. J. Med., 319, 1 397-1400 (1988). 
4) K. S. Weiss, Ann. Intern. Med., 116, 347 (1992).

5 ) S. Saitoh, H. Kumada, K. Ikeda, K. Chayama, Y. Arase and M. Unakami, Syokakita (Gastroenterology), 14, 352-355 (1991).

6 ) Y. Nakamoto, Y. Inagaki, Y. Kitano, H. Ogino, H. Kawai, M. Tanei, K. Nishimura, E. Matushita, K. Urabe, S. Kaneko, M. Uura and K. Kobayashi, Kanzo (Acta Hepatol. Jap.), 32, 863-867 (1991).

7 ) H. Ueda, A. Ishikawa, S. Itoh, M. Kusaka, H. Azuma, T. Suzuki, N. Takasaki, K. Isurugi, N. Ueno, A. Demura, T. Moriguchi, S. Sakane and N. Osawa, Hinyokika Kiyo (Acta Urol. Jap.) , 38, 1165-1169 (1992).

$8)$ S. Shoji, N. Miyamoto, H. Hosoi, A, Makita, K. Yokoyama, R. Nagayama, H. Takikawa, K. Miyake and M. Yamanaka, Nippon Shokakibyo Gakkai Zasshi (Jap. J. Gastroenterol.), 89, 2735-2738 (1992).

9 ) T. Abe, M. Suga, A. Ono, K. Yonezawa, F.Ishibashi, M. Tosaka, T. Tokunoh, A. Yawata, S. Sasaki, T. Kobayashi, T. Yabana, A. Yachi and Y. Yoshida, Nippon Shokakibyo Gakkai Zasshi (Jap. J. Gastroenterol.), 90, 818-822 (1993).

10) E. Tanaka and T. Sodeyama, Chiryogaku (Biomedicine and Therapeutics), 27, 109-111 (1993).

11) S. Ukae, E. Tomita, K. Ikeda, H. Tsutsumi, S. Imai, T. Ohsato and S. Chiba, Nippon Shonika Gakkai Zasshi (J. Jap. Pediatr. Soc.) , 98, 122-123 (1993).

12) K. Takeda, O. Kawashima, K. Sakamoto, M. Takagi, Y. Mizuhara, M. Ohata, J. Hirakawa, H. Nakajima, M. Yamauchi and G. Toda, Shokakika (Gastroenterology), 19, 409-413 (1994).

13) H. Smedley, M. Katrak, K. Sikora and T. Wheeler, Br. Med. J., 286, 262-264 (1983).

14) L. Honigsberger, J. W. Fielding and T. J. Priestman, Br. Med. J., 286, 719 (1983).

15) H. Imaoka, M. Takahashi, S. Yorifuji and Y. Nakamura, Rinsho Noha (Clin. Electroencephalogr), 29, 60-62 (1987).

16) H. Imaoka, Y. Nakamura, M. Kitaguchi and M. Takahashi, Rinsho Noha (Clin. Electroencephalogr), 30, 80-83 (1988).

17) N. Hirota, Y. Hamada, Y. Kawanami, H. Suzuki, K. Takahashi, J. Uchino, M. Koga, H. Tajima, T. Minamino and M. Yano, Seishin Igaku (Clin. Psychiatr.), 30, 177-182 (1988).

18) T. Takahashi, Y. Ichimiya and R. Iizuka, Seishin Igaku (Clin. Psychiatr.), 32, 93-95 (1990).

19) H. L. A. Janssen, L. Berk, M. Vermeulen and S. W. Schalm, Lancet, 8730, 1580 (1990). 